Published in final edited form as:

ACS Chem Neurosci. 2020 September 16; 11(18): 2827-2835. doi:10.1021/acschemneuro.0c00389.

\title{
A Pentacyclic Triterpene from Ligustrum lucidum Targets $\gamma$ - Secretase
}

\author{
Wenjie Luo\#, \\ Laboratory of Molecular and Cellular Neuroscience, The Rockefeller University, New York, New \\ York 10065, United States
}

Fanny C. F. Ip\#, Division of Life Science, State Key Laboratory of Molecular Neuroscience, and Molecular Neuroscience Center, The Hong Kong University of Science and Technology, Kowloon, Hong Kong, China; Hong Kong Center for Neurodegenerative Diseases, Hong Kong Science Park, Hong Kong, China; Guangdong Provincial Key Laboratory of Brain Science, Disease and Drug Development, Shenzhen-Hong Kong Institute of Brain Science, HKUST Shenzhen Research Institute, Shenzhen, Guangdong, China 518057

\section{Guangmiao Fu,}

Division of Life Science, State Key Laboratory of Molecular Neuroscience, and Molecular Neuroscience Center, The Hong Kong University of Science and Technology, Kowloon, Hong Kong, China

\section{Kit Cheung,}

Division of Life Science, State Key Laboratory of Molecular Neuroscience, and Molecular Neuroscience Center, The Hong Kong University of Science and Technology, Kowloon, Hong Kong, China

\section{Yuan Tian,}

\footnotetext{
Corresponding Authors Nancy Y. Ip - Division of Life Science, State Key Laboratory of Molecular Neuroscience, and Molecular Neuroscience Center, The Hong Kong University of Science and Technology, Kowloon, Hong Kong, China; Hong Kong Center for Neurodegenerative Diseases, Hong Kong Science Park, Hong Kong, China; Guangdong Provincial Key Laboratory of Brain Science, Disease and Drug Development, Shenzhen-Hong Kong Institute of Brain Science, HKUST Shenzhen Research Institute, Shenzhen, Guangdong, China 518057; boip@ ust.hk; Subhash C. Sinha - Laboratory of Molecular and Cellular Neuroscience, The Rockefeller University, New York, New York 10065, United States; sus2044@med.cornell.edu.

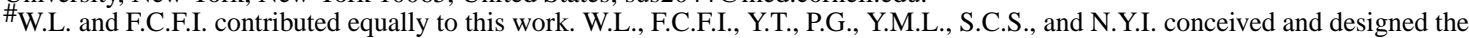
experiments. W.L., A.S., Y.T., X.W., V.B., G.F., K.C., E.Y.L.C., and Y.H. performed the experiments. W.L., F.C.F.I., S.C.S., Y.T., G.F., and N.Y.I. analyzed the data. W.L., F.C.F.I., Y.M.L., S.C.S., and N.Y.I wrote the manuscript. All the authors read and approved the final manuscript.

P.G.: Deceased.

Supporting Information

The Supporting Information is available free of charge at https://pubs.acs.org/doi/10.1021/acschemneuro.0c00389.

Additional materials and methods; extraction methods and results of screening of herbal extracts; HPLC chromatograms of herbal fractions, semisynthetic trans-OCMA, RF9-C31, and RF9-C32; synthetic scheme of trans-OCMA and OABC; analytical method and spectral data for chemically semisynthesized trans-OCMA; bioactivity evaluation of OABC and other OA/MA derivatives; animal and compound administration; preparation of mouse brains and plasma; mass spectrometry methods for trans-OCMA and OABC; spectra data (PDF)

Y.M.L. is a coinventor of intellectual property (i.e., assay for gamma secretase activity and screening method for gamma secretase inhibitors) owned by MSKCC and licensed to Jiangsu Continental Medical Development.

The authors declare no competing financial interest.
} 
Laboratory of Molecular and Cellular Neuroscience, The Rockefeller University, New York, New York 10065, United States

\section{Yueqing $\mathrm{Hu}$,}

Division of Life Science, State Key Laboratory of Molecular Neuroscience, and Molecular Neuroscience Center, The Hong Kong University of Science and Technology, Kowloon, Hong Kong, China

\section{Anjana Sinha,} Laboratory of Molecular and Cellular Neuroscience, The Rockefeller University, New York, New York 10065, United States

\section{Elaine Y. L. Cheng,}

Division of Life Science, State Key Laboratory of Molecular Neuroscience, and Molecular Neuroscience Center, The Hong Kong University of Science and Technology, Kowloon, Hong Kong, China

\section{Xianzhong Wu,}

Chemical Biology Program, Memorial Sloan Kettering Cancer Center, New York, New York 10065, United States

\section{Victor Bustos,}

Laboratory of Molecular and Cellular Neuroscience, The Rockefeller University, New York, New York 10065, United States

Paul Greengard ${ }^{\bigcirc}$, Laboratory of Molecular and Cellular Neuroscience, The Rockefeller University, New York, New York 10065, United States

\section{Yue-Ming Li,} Chemical Biology Program, Memorial Sloan Kettering Cancer Center, New York, New York 10065, United States

\section{Subhash C. Sinha,} Laboratory of Molecular and Cellular Neuroscience, The Rockefeller University, New York, New York 10065, United States

\section{Nancy Y. Ip}

Division of Life Science, State Key Laboratory of Molecular Neuroscience, and Molecular Neuroscience Center, The Hong Kong University of Science and Technology, Kowloon, Hong Kong, China; Hong Kong Center for Neurodegenerative Diseases, Hong Kong Science Park, Hong Kong, China; Guangdong Provincial Key Laboratory of Brain Science, Disease and Drug Development, Shenzhen-Hong Kong Institute of Brain Science, HKUST Shenzhen Research Institute, Shenzhen, Guangdong, China 518057

\section{Abstract}

Amyloid-beta peptides generated by $\beta$-secretase- and $\gamma$-secretase-mediated successive cleavage of amyloid precursor protein are believed to play a causative role in Alzheimer's disease. Thus, reducing amyloid-beta generation by modulating $\gamma$-secretase remains a promising approach for Alzheimer's disease therapeutic development. Here, we screened fruit extracts of Ligustrum 
lucidum Ait. (Oleaceae) and identified active fractions that increase the C-terminal fragment of amyloid precursor protein and reduce amyloid-beta production in a neuronal cell line. These fractions contain a mixture of two isomeric pentacyclic triterpene natural products, 3-O-cis- or 3$O$-trans-p-coumaroyl maslinic acid (OCMA), in different ratios. We further demonstrated that trans-OCMA specifically inhibits $\gamma$-secretase and decreases amyloid-beta levels without influencing cleavage of Notch. By using photoactivatable probes targeting the subsites residing in the $\gamma$-secretase active site, we demonstrated that trans-OCMA selectively affects the S1 subsite of the active site in this protease. Treatment of Alzheimer's disease transgenic model mice with trans-OCMA or an analogous carbamate derivative of a related pentacyclic triterpene natural product, oleanolic acid, rescued the impairment of synaptic plasticity. This work indicates that the naturally occurring compound trans-OCMA and its analogues could become a promising class of small molecules for Alzheimer's disease treatment.

\section{Graphical Abstract}

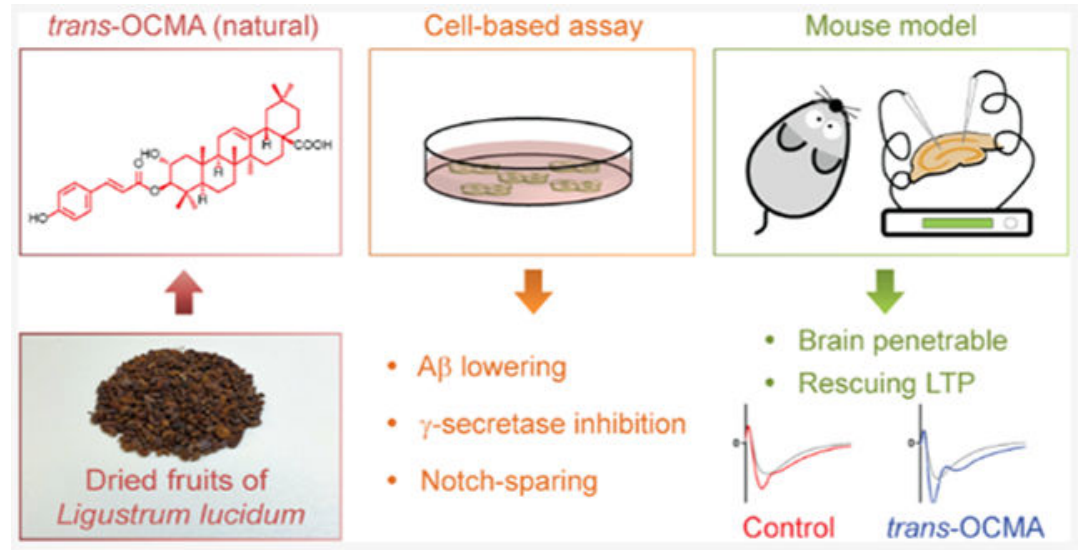

\section{Keywords}

Alzheimer's disease; amyloid precursor protein; beta-amyloid; synaptic plasticity; oleanolic acid; secretase

\section{INTRODUCTION}

Alzheimer's disease (AD) is a neurodegenerative disease that primarily affects the elderly and is characterized by the deposition of amyloid plaques in the brain. ${ }^{1}$ Given its increasing prevalence due to population aging, $\mathrm{AD}$ is a major threat to society. As there is no effective treatment that can halt or slow $\mathrm{AD}$ progression, screening for molecules with therapeutic potential for $\mathrm{AD}$ treatment is the most in-demand yet challenging task. ${ }^{2}$ Accumulating evidence suggests that neurotoxic amyloid-beta $(\mathrm{A} \beta)$ peptides are one of the major causative factors of $\mathrm{AD}{ }^{3-6} \mathrm{~A} \beta$ peptides are generated by the sequential cleavage of amyloid precursor protein (APP) by $\beta$-secretase (BACE1), generating the C-terminal fragment of APP (APP$\mathrm{CTF}$ ), which is in turn cleaved by $\gamma$-secretase (GS) to yield $\mathrm{A} \beta$ peptides. $\mathrm{A} \beta$ peptides are 38-43 amino acids long, and $\mathrm{A} \beta_{42}$ is the major constituent of amyloid plaques deposited in the $\mathrm{AD}$ brain. ${ }^{7}$ Numerous studies have shown that $\mathrm{A} \beta_{42}$ is most prone to aggregation and 
that its aggregated forms have neurotoxic activities including decreasing synaptic number and inhibiting long-term potentiation (LTP) ${ }^{8} \mathrm{~A} \beta$ accumulation represents one of the major AD biomarkers ${ }^{9}$ and is likely a key driver of AD pathogenesis. ${ }^{8}$ Indeed, targeting BACE1 and GS is a compelling therapeutic approach for AD drug development. ${ }^{10}$

GS is an intramembrane protease complex that cleaves over 100 transmembrane proteins. 11,12 The GS complex comprises multiple protein subunits including presenilin-1/2 (PS1/2), presenilin enhancer 2, nicastrin, and anterior pharynx-defective 1. PS1/2 are the catalytic subunits of the complex, ${ }^{12-14}$ and their autosomal dominant alleles are major genetic causes of some cases of familial AD. ${ }^{15}$ Over the past 20 years, more than a dozen GS inhibitors (GSIs) and GS modulators have been identified, some of which entered clinical trials. ${ }^{16-18}$ However, none succeeded because of their nonspecific inhibition of Notch signaling, resulting in side-effects including gastrointestinal discomfort, skin lesions, and worsening cognitive function. ${ }^{19}$ These findings indicate an urgent need to identify alternative inhibitors/ modulators of GS.

Traditional Chinese medicine and medicinal plants have been used to treat human diseases and maintain health in China and neighboring countries for more than 3000 years. ${ }^{20,21}$ These plants contain innumerable bioactive compounds but remain a largely untapped resource for drug development. ${ }^{22}$ Reportedly, a large proportion of active compounds and medicines currently used for central nervous system disorders are of natural origin or are modified from such compounds. ${ }^{23}$ Our laboratory has been investigating extracts of medicinal plants with reported antiaging effects to identify potential druglike analogues/ derivatives for the treatment of $\mathrm{AD}$ and other neurological disorders. ${ }^{24,25}$ We have screened several herbal plant extracts and performed activity-guided fractionation of the fruit extracts of Ligustrum lucidum Ait., a flowering plant of the olive family (Oleaceae), ${ }^{26}$ to identify active fractions and pure constituents that decrease $\mathrm{A} \beta$ production.

Here, we report that two active fractions, RF9-C31 and RF9-C32, from the fruit extracts of $L$. lucidum reduced $\mathrm{A} \beta$ production in neuroblastoma cells overexpressing human APP. These fractions primarily contained maslinic acid (MA) derivatives, 3-O-cis-p-coumaroylmaslinic acid (cis-OCMA) and 3-O-trans-p-coumaroyl-maslinic acid (trans-OCMA) (Figure 1). We also evaluated eight synthetic trans-OCMA and other oleanolic acid (OA) and MA derivatives, including the previously described oleanolic acid benzyl carbamate ${ }^{27}$ (OABC) derivative and showed that both trans-OCMA and OABC reduced $\mathrm{A} \beta$ production by inhibiting GS without affecting Notch cleavage. Furthermore, we showed that injection of trans-OCMA or OABC alleviated the synaptic plasticity impairment in an AD transgenic model mice. Our results collectively indicate that trans-OCMA isolated from L. lucidum is a Notch-sparing GSI that exhibits a potential beneficial effect by alleviating AD pathology.

\section{RESULTS}

\section{Active L. lucidum Fruit Extract Fractions Increase APP-CTF and Reduce A $\beta$ Production.}

Our primary screening identified several herb extracts whose activity increased APP-CTFs levels in neuroblastoma N2a cells stably expressing human APP695 ("N2a695 cells" hereafter) (Figure S1). In this study, we focused on L. lucidum fruit extracts and performed 
further fractionation and purification to obtain various fractions (Figure S2). To identify the active fractions, N2a695 cells were treated with different fractions of $L$. lucidum fruit extracts, including fractions RF9-C24-RF9-C32, and their effects on $\mathrm{A} \beta$ production were determined. Most of these fractions primarily contained one compound, whereas fractions RF9-C31 and RF9-C32 contained two compounds in unequal ratios, as evident from the HPLC chromatograms (Figures S3 and S4). We found that the cellular APP-CTF levels increased in cells treated with RF9-C31 or RF9-C32 (Figure 2A). We further examined the activities of these two fractions in $\mathrm{A} \beta$ production and demonstrated that both fractions decreased extracellular $\mathrm{A} \beta$ levels in the cell medium and increased the cellular APP-CTF level in a dose-dependent manner (Figure 2B). Moreover, by using metabolic labeling with ${ }^{35} \mathrm{~S}$-methionine/cysteine, we showed that RF9-C31 treatment inhibited the production of newly synthesized endogenous murine $\mathrm{A} \beta$ and $\mathrm{A} \beta_{1-40 / 42}$ in rat primary neurons (Figure $2 \mathrm{C}$ ). Collectively, these results demonstrate that both RF9-C31 and RF9-C32 inhibit A $\beta$ production and increase APP-CTF, suggesting inhibition of GS-mediated APP-CTF cleavage.

\section{trans-OCMA Reduces A $\beta$ Production in N2a695 Cells and Modulates GS Activity In Vitro.}

Spectral data analysis revealed that RF9-C31 and RF9-C32 contained varying amounts of stereoisomeric cis- and trans-OCMA, with RF9-C31 containing more trans-OCMA (Figure S4). To confirm that trans-OCMA is the active A $\beta$-lowering component of RF9-C31, we designed and synthesized trans-OCMA from the readily available starting material, OA (Scheme $\mathrm{S} 1$ ), and evaluated its $\mathrm{A} \beta$-lowering activity in N2a695 cells. Accordingly, transOCMA reduced the levels of $\mathrm{A} \beta_{38}, \mathrm{~A} \beta_{40}$, and $\mathrm{A} \beta_{42}$ in a dose-dependent manner (Figure $3 \mathrm{~A})$. To verify that trans-OCMA reduces $\mathrm{A} \beta$ production by targeting $\mathrm{GS}$, we performed an in vitro GS activity assay. ${ }^{28,29}$ As shown in Figure 3B, trans-OCMA inhibited the production of all three $\mathrm{A} \beta$ species with $\mathrm{IC}_{50}$ values of $1.17,0.30$, and $0.46 \mu \mathrm{M}$ for $\mathrm{A} \beta_{40}$, $\mathrm{A} \beta_{42}$, and $\mathrm{A} \beta_{38}$, respectively, suggesting that trans-OCMA directly inhibits GS activity. The difference in the $\mathrm{IC}_{50}$ values for $\mathrm{A} \beta_{40}$ and $\mathrm{A} \beta_{42}$ is approximately 4 fold, suggesting that this compound has moderate selectivity against $\mathrm{A} \beta_{42}$.

\section{trans-OCMA Modulates the Active Site of GS.}

PS1 is the catalytic component of the GS complex. ${ }^{30}$ Active site-directed, photoaffinity labeling probes have proven to be an effective tool for providing insight into the GS catalytic active site located at the interface of 2 PS1 subunits. ${ }^{18}$ To examine how trans-OCMA affects GS activity, we performed photoaffinity labeling of the enzyme using active site-directed probes $^{31}$ in the presence or absence of trans-OCMA. The photophore walking probes used in the competitive assay, JC-8, L646, L505, and GY-4, label the S1' ${ }^{\prime}, \mathrm{S} 2$, S3', and S1 subsites, respectively, within the active site (i.e., PS1) of the GS complex. trans-OCMA completely abolished PS1 labeling by GY-4. While trans-OCMA decreased labeling by JC- 8 and increased that by L646, it did not alter labeling by L505 (Figure 3C). These results suggest that, distinct from other known GSIs, trans-OCMA affects the S1 substrate-enzyme interface and induces a unique conformational change of the GS enzyme complex. ${ }^{31}$ 


\section{trans-OCMA Does Not Affect Notch Cleavage.}

As mentioned above, GSIs evaluated in clinical trials for patients with AD or mild cognitive impairment were unsuccessful or even exacerbated cognitive function impairment. ${ }^{19,32}$ One possible explanation is that these GSIs interfered with the cleavage of Notch by GS, consequently initiating side effects due to the inhibition of the physiological functions of the proteolytic fragment of Notch (Notch intracellular domain [NICD]). ${ }^{33}$ Therefore, we examined whether trans-OCMA inhibits Notch cleavage by detecting the level of NICD generated from Notch $\Delta \mathrm{E}$-myc, a substrate for GS. In N2a cells that expressed Notch $\Delta \mathrm{E}$ myc, administration of the GSI L-685,458 potently inhibited the production of NICD fragment, as indicated by an anti-myc antibody or specific antibody against the cleaved Nterminal of NICD (Figure 3D, right panel). However, trans-OCMA did not affect the cleavage of full-length Notch into the NICD product (Figure 3D, left panel). These results suggest that trans-OCMA is a GSI that does not cleave Notch, making it a Notch-sparing GSI. ${ }^{34}$

\section{Semisynthetic trans-OCMA as Well as OA and MA Derivatives Reduce A $\beta$ Production in Cells.}

The synthesis of trans-OCMA from OA was achieved in six chemical steps, with an overall yield of approximately $2 \%$ (Scheme S1 and Figure S2). To examine the role of the coumaroyl moiety in trans-OCMA on its activity, we obtained parent compounds OA and MA (Figure 1) as well as several derivatives including OA-1-OA-4 and MA-1-MA-5 (Table 1). ${ }^{35-38}$ First, we determined the effects of MA in N2a695 cells by measuring the total $A \beta$ level using Western blot analysis. We found that $\mathrm{A} \beta$ levels increased greatly compared to the DMSO control (data not shown). We subsequently evaluated OA and all OA and MA analogues, including OA-1-OA-4 and MA-1-MA-5, in N2a695 cells and determined the effects on $\mathrm{A} \beta$ production by ELISA. Thus, we found that, unlike trans-OCMA, the majority of compounds increased $\mathrm{A} \beta$ levels. OA increased both $\mathrm{A} \beta_{40}$ and $\mathrm{A} \beta_{42}$ levels by $15-25 \%$, while all $\mathrm{OA}$ and MA derivatives except OA-1 and OA-2 considerably increased $\mathrm{A} \beta_{42}$ levels. Only OA-1 reduced both $\mathrm{A} \beta_{40}$ and $\mathrm{A} \beta_{42}$ levels. Based on these experiments, the GS inhibitory activity of trans-OCMA is attributable to the presence of a coumaroyl moiety at its $\mathrm{C}_{3}$ position.

Meanwhile, we also prepared and evaluated the previously described benzyl carbamate derivative of OA: OABC. ${ }^{27}$ We selected OABC for our study, because carbamate compounds are nonnative substrates of endogenous lipase enzymes and are cleaved less efficiently than an ester in vivo. ${ }^{39}$ In addition, OABC can be prepared in a single-step reaction (Figure S5) by reacting OA with benzyl isocyanate in the presence of copper chloride in hot toluene. ${ }^{40} \mathrm{We}$ found that $\mathrm{OABC}$ reduced the production of $\mathrm{A} \beta_{40}$ and $\mathrm{A} \beta_{42}$ with activities comparable to that of trans-OCMA (Figure 3B and S5). The $\mathrm{IC}_{50}$ values of OABC against $\mathrm{A} \beta_{40}$ and $\mathrm{A} \beta_{42}$ were 0.57 and $0.65 \mu \mathrm{M}$, respectively. On the other hand, $\mathrm{OABC}$ treatment reduced the $\mathrm{A} \beta$ level in $\mathrm{N} 2 \mathrm{a} 695$ cell-conditioned media by $10-40 \%$. Furthermore, $\mathrm{OABC}$ and $\mathrm{OA}$ at $5 \mu \mathrm{M}$ exhibited no toxicity in N2a695 cells in an MTT assay (Figure S5). 


\section{trans-OCMA and OABC Rescue Synaptic Plasticity Impairment in Alzheimer's Disease Transgenic Model Mice.}

As $\mathrm{A} \beta$ levels increase, $\mathrm{A} \beta$ monomers aggregate into oligomers and bind to excitatory synapses in the hippocampus, consequently impairing synaptic plasticity. ${ }^{3-5}$ In APP/PS1 mice, a transgenic mouse model of $\mathrm{AD}$, synaptic plasticity impairment manifests as a reduction of LTP. ${ }^{41}$ Given that trans-OCMA and OABC inhibit A $\beta$ production, we investigated their effects on LTP impairment in APP/PS1 mice. APP/PS1 mice exhibited a significant impairment in field excitatory postsynaptic potential (fEPSP) compared to their nontransgenic littermates. Treatment with either trans-OCMA or OABC significantly improved LTP and rescued the LTP impairment in APP/PS1 mice (Figure 4A). To determine the brain penetration of trans-OCMA and OABC, we administered the compounds intraperitoneally and measured their concentrations in plasma and brain tissue in C57BL/6 mice after a single injection. Both trans-OCMA and OABC showed their ability to cross the blood-brain barrier, reaching the micromolar range with peak concentrations (i.e., $C_{\max }$ ) in the brain of 1.75 and $2.09 \mu \mathrm{M}$ for trans-OCMA and OABC, respectively (Figure 4B and Table 2).

\section{DISCUSSION}

Developing natural products as specific GSIs or GS modulators ${ }^{42}$ to reduce $\mathrm{A} \beta$ generation from APP is a promising approach for AD drug development. ${ }^{43,44}$ In the present study, we identified trans-OCMA, which reduces the processing of APP into A $\beta$, as a naturally occurring and Notch-sparing GSI. trans-OCMA is one of the 40 known triterpenes and the major active constituent in the fruit of L. lucidum. It was first isolated from Zizyphus jujuba ${ }^{45}$ and subsequently from Tetracera boiviniana, ${ }^{46}$ Prinsepia utiliz, ${ }^{47}$ and nu zhen zi, the dried ripe fruit of the evergreen tree L. lucidum in this study. L. lucidum is designated a "top-tier" medicine owing to its safety for long-term use for antiaging purposes. In addition to its antiaging property, L. lucidum extract possesses antiosteoporotic, antioxidative, antidiabetic, and antitumor properties ${ }^{26,48,49}$ and is a constituent of the Bushen-Yizhi formula, which attenuates behavioral deficits in AD transgenic mice. ${ }^{50}$ Apart from transOCMA, glucosides of $L$. lucidum have been shown to activate the transcription factor CREB, which is associated with memory enhancement. ${ }^{51}$ Therefore, it will be interesting to investigate the combinational effects of different ingredients in the herb.

trans-OCMA inhibited the GS cleavage of APP but did not alter the $\mathrm{A} \beta_{42} / \mathrm{A} \beta_{40} / \mathrm{A} \beta_{38}$ ratio. Unlike most existing GSIs/GS modulators, trans-OCMA specifically inhibits APP processing and does not cleave Notch, which is another common substrate of GS, suggesting that trans-OCMA is a Notch-sparing GSI. It differs from other Notch-sparing GSIs (e.g., CS-1 and BMS-708163) that inhibit two or four photoprobes (e.g., JC-8, L646, GY-4, and L505) from binding to PS1-NTF. ${ }^{52,53}$ trans-OCMA only competes with the binding of GY-4 to the S1 site of the GS active pocket. Nevertheless, it remains unclear whether it does so directly or indirectly by allosterically modulating the conformation of PS1. Because the lipid microenvironment surrounding GS can influence its enzyme activity, ${ }^{54}$ there is a possibility that trans-OCMA interferes with the lipid microenvironment owing to its hydrophobicity, thereby affecting the conformation of PS1. Therefore, further investigation is required to 
understand the mechanism underpinning the GSI activity of trans-OCMA, specifically whether its GY-4-competing activity accounts for its Notch-sparing activity.

To our knowledge, this study is the first to show the modulatory effect of the antiaging medicinal herb, L. lucidum, in APP processing and that its active ingredient, trans-OCMA, has an in vivo effect on the central nervous system. While the molecular size of transOCMA is greater than 600, and its physicochemical properties are unfavorable for central nervous system applications, ${ }^{55}$ trans-OCMA can be detected in the brain upon systemic injection and reverses functional deficits in $\mathrm{AD}$ model mice. Moreover, as the development of synthetic compounds facilitates drug development, we have established a six-step synthetic route to generate trans-OCMA from OA, which is abundant in olive plants. $.56,57$ This semisynthetic trans-OCMA exhibits a GS inhibitory activity similar to that of natural trans-OCMA and reduces $\mathrm{A} \beta_{40}$ and $\mathrm{A} \beta_{42}$ production in cells. The non-natural OA carbamate derivative, $\mathrm{OABC}$, which is prepared semisynthetically, conveniently starting with OA in a single step, was also active in our assays, including in the $\mathrm{A} \beta$ production assay in cells and the GSI activity assay in vitro. Systemic delivery of trans-OCMA or its carbamate derivative $\mathrm{OABC}$ into $\mathrm{AD}$ transgenic model mice alleviates functional defects. Thus, transOCMA and OABC are promising candidates for further therapeutic development.

\section{METHODS}

\section{Plant Extract Fractions, Semisynthetic Natural Product, and Analogues.}

Ligustrum lucidum Aiton fruits were purchased from a reputable vendor in Hong Kong Special Administrative Region of China, and a voucher of specimen (TCM-009) was kept at the Molecular Neuroscience Center at the Hong Kong University of Science and Technology. Fractionation of L. lucidum to yield RF9-C24-RF9-C32 is described in Figure S2. While RF9-C31 and RF9-C32 contained varying amounts of cis- or trans-OCMA, other fractions contained a single major compound of purity over 90\% (Figures S3 and S4). transOCMA was semisynthesized in six steps using OA as the starting backbone. The synthetic route is shown in Scheme $\mathrm{S} 1$, and the identity of compounds was characterized by ${ }^{13} \mathrm{C}$ and ${ }^{1} \mathrm{H}$ NMR (Figure S6). OABC was semisynthesized in one step, ${ }^{27}$ and $\mathrm{A} \beta$ lowering activity is shown in Figure S5.

\section{Cell Lines.}

N2a695 cells were available in-house and were cultured in 1:1 Opti-MEM Reduced Serum Media (Life Technologies): Dulbecco's modified Eagle's medium ([+] 4.5 g/L D-glucose; [+] L-glutamine; [-] sodium pyruvate (Life Technologies)) supplemented with 5\% fetal bovine serum, $0.4 \%$ Penstrep, and $0.4 \%$ Geneticin and incubated at $37{ }^{\circ} \mathrm{C}$ in $5 \% \mathrm{CO}_{2}$. HeLaS3 cells were purchased from Cell Culture Company, and membranes were prepared as previously described. ${ }^{58}$

\section{Compound Treatment.}

Six-well tissue culture plates (Corning) were seeded with N2a695 cells $\left(4.0 \times 10^{5}-4.5 \times 10^{5}\right.$ cells $/ \mathrm{mL}, 2 \mathrm{~mL} /$ well $)$ and incubated overnight at $37{ }^{\circ} \mathrm{C}\left(5 \% \mathrm{CO}_{2}\right.$ atmosphere). The next day, the cell media (>95\% confluent) was exchanged with fresh media containing fractions or 
synthetic trans-OCMA or OABC (10 $\mu \mathrm{M}$ or lower concentration, prepared from $10 \mathrm{mM}$ solution in DMSO), and cells were further incubated for $5 \mathrm{~h}$. Cell media was collected for determining A $\beta$ concentration. Remaining cells were scraped in cold Dulbecco's PBS buffer $(1 \mathrm{~mL})$ in the presence of EDTA-free protease inhibitor (Roche) and centrifuged for $1 \mathrm{~min}$ at $13000 \mathrm{rpm}$ at $4{ }^{\circ} \mathrm{C}$. Resulting cell pellets were lysed in 3\% SDS by sonication to afford cell lysates for performing Western blotting experiments.

\section{Western Blots.}

Cells were lysed with RIPA buffer, and the protein concentrations were determined by BCA assay (Pierce). The same amount of protein lysate $(50 \mu \mathrm{g})$ per sample was loaded for SDSPAGE and transferred to PVDF membranes for blotting following electrophoresis. Full length APP (APP-FL) was detected with 6E10 (Covance). Full length Notch was detected with the 9E10 myc antibody (Invitrogen). The NICD specific antibody was an antibody against cleaved Notch1 (Val1744, Cell signaling). APP-CTFs were detected with the RU369 antibody. ${ }^{59}$ PS1-NTF antibody was detected with Ab14. ${ }^{60}$ Total A $\beta$ in the media was determined by immunoprecipitation with the 4G8 antibody and blotting with the $6 \mathrm{E} 10$ antibody.

\section{Measurement of $A \beta$ by ELISA.}

The levels of $\mathrm{A} \beta_{38}, \mathrm{~A} \beta_{40}$, and $\mathrm{A} \beta_{42}$ in culture media were measured in a 96-well V-Plex Plus MSD (Mesoscale Discovery) plate using the A $\beta$ Peptide Panel 1 (6E10) Kit (catalog number K15200G) by following the manufacturer's instructions. The signals for $A \beta$ were measured using the SQ120 MSD ELISA reader. In some experiments, the levels of $A \beta_{40}$ and $\mathrm{A} \beta_{42}$ in the culture media were measured by using an ELISA kit specific for human $\mathrm{A} \beta_{40}$ (Thermo Fisher \# KHB3481) or A $\beta_{42}$ (Thermo Fisher \# KHB3441) following the manufacturer's instructions. Signals for $\mathrm{A} \beta$ were measured using a PerkinElmer Envision ELISA reader.

\section{Measuring Endogenous Rat A $\beta$ Synthesis in Primary Rat Neurons by Metabolic Labeling.}

Primary rat prenatal cortical neurons were treated with 0,1 , or $5 \mu \mathrm{M}$ RF9-C31 for $4 \mathrm{~h}$ and then metabolically labeled for $6 \mathrm{~h}$ using ${ }^{35} \mathrm{~S}$-methionine/cysteine protein labeling mix (PerkinElmer). The levels of murine $\mathrm{A} \beta_{1-40 / 42}$ and $\mathrm{A} \beta_{11-40 / 42}$ species in the media were determined by immunoprecipitation using antibody $4 \mathrm{G} 8$ followed by SDS-PAGE and autoradiography. ${ }^{61}$

\section{$\gamma$-Secretase Activity Assay.}

HeLa membranes were labeled with active site-directed photoprobes L646, L505, GY-4, or JC-8 in the presence or absence of trans-OCMA. This was followed by Western blot of PS1NTF and -CTF after pull-down with streptavidin resin. ${ }^{58}$ In vitro GS activity assay by incubating recombinant APP-CTF substrate (SB4) with cell membranes prepared from HeLa cells was performed, as described previously. ${ }^{28,61,62}$ 


\section{Notch Cleavage Assay.}

$\mathrm{N} 2 \mathrm{a}$ cells were transfected with the Notch $\Delta \mathrm{E}$ construct (myc-tagged at $\mathrm{NT})^{61}$ for 2 days followed with treatment with trans-OCMA or L-685,458 for $24 \mathrm{~h}$. The expression of fulllength Notch was analyzed by Western blot using the anti-myc antibody. The cleaved NICD was detected with a cleavage-specific antibody (Notch1 Val-1744, Cell Signaling).

\section{Animals and Electrophysiological Measurement.}

The AD model mice used were APP/PS1 double-transgenic (B6C3-Tg [APPswe, PS1dE9]85Dbo/J) mice obtained from Jackson Laboratory. They were maintained and bred in the Animal and Plant Care Facility of The Hong Kong University of Science and Technology (HKUST). The experimental protocols were approved by the Animal Ethics Committee of HKUST and conducted in accordance with the Code of Practice Care and Use of Animals for Experimental Purposes of Hong Kong. trans-OCMA in $85 \mu \mathrm{mol} / \mathrm{kg}$ body weight (injection volume $10 \mathrm{~mL} / \mathrm{kg}$ ) was injected intraperitoneally into 6-7 month old APP/PS1 mice daily for 4 weeks. Mice injected with vehicle (3\% dimethyl sulfoxide/10\% Tween- 80 in water (3:10:87 by volume) served as controls. LTP was measured in the hippocampal Schaffer-collateral (SC) pathway after high-frequency stimulation (HFS). To measure LTP after the 4 week treatment, we sacrificed the mice by decapitation. Whole brains were immediately resected and soaked in ice-cold artificial cerebrospinal fluid (aCSF) supplemented in $95 \% \mathrm{O}_{2} / 5 \% \mathrm{CO}_{2}$. Brain slices $(300 \mu \mathrm{m})$ were then prepared using a vibratome (HM650V; Thermo Fisher Scientific) and soaked in oxygenated aCSF for $2 \mathrm{~h}$ at $32{ }^{\circ} \mathrm{C}$ for recovery. LTP formations were recorded using a multielectrode array system (MED-64, Panasonic International, Inc.) and paradigms were conducted as previously described. ${ }^{24,25}$

\section{Pharmacokinetic Study.}

trans-OCMA and OABC were prepared in 3\% dimethyl sulfoxide/10\% Tween-80 in water (3:10:87 by volume). C57BL/6 mice at 12 weeks old (males) were injected with the compound at a dose of $85 \mu \mathrm{mol} / \mathrm{kg}(52.5 \mathrm{mg} / \mathrm{kg}$ trans-OCMA; $50.0 \mathrm{mg} / \mathrm{kg}$ OABC) body weight (injection volume $10 \mathrm{~mL} / \mathrm{kg}$ ). Samples were collected at different postinjection time points ( $n=4$ per time point, $0.25,0.5,1,2,3,4,6,8,24,48,72,96 \mathrm{~h}$ ) from mice under deep anesthesia by isoflurane inhalation. Plasma was separated from blood collected by cardiac puncture, and the whole brain was collected after transcardiac perfusion with phosphate-buffered saline for $15 \mathrm{~min}$. The amount of trans-OCMA and OABC in the brain or plasma samples was determined using triple-Q mass spectrometry (AB SCIEX 4500 QTRAP system). Details of the detection parameters are provided in the Supporting Information.

\section{Statistical Analysis.}

The investigators who performed the electrophysiology and pharmacokinetic studies were blinded to the genotypes and treatments of the mice. All data are expressed as arithmetic mean \pm SEM. All statistical analyses were performed using GraphPad Prism ver. 6.0. The significance of differences was assessed by using unpaired Student's $t$ test or one- or two- 
way ANOVA followed by the Bonferroni post hoc test as indicated. The level of significance was set at $P<0.05$.

\section{Supplementary Material}

Refer to Web version on PubMed Central for supplementary material.

\section{ACKNOWLEDGMENTS}

The authors would like to thank Dr. William J. Netzer, Dr. Gen He, Dr. Marc Flajolet, and Prof. Kit-Yu Fu for their helpful discussion. The technical assistance of Mr. Ka Chun Lok and Mr. Wenbo Lyu in this work is appreciated.

Funding

This study was supported by the Fisher Center for Alzheimer's Research Foundation to P.G., the JPB Foundation (Grant \#839) to S.C.S., the Research Grants Council of Hong Kong [the Theme-Based Research Scheme (T13-607/12R)], the National Key R\&D Program of China (2017YFE0190000 and 2018YFE0203600), the Areas of Excellence Scheme of the University Grants Committee (AoE/M-604/16), the Innovation and Technology Commission (ITCPD/17-9 and UIM/323), the Guangdong Provincial Key S\&T Program (2018B030336001), the Guangdong Provincial Fund for Basic and Applied Basic Research (2019B1515130004), the Shenzhen Knowledge Innovation Program (JCYJ20180507183642005 and JCYJ20170413173717055) to N.Y.I., and NIH grants R01NS096275 and RF1AG057593 to Y.M.L.

\section{REFERENCES}

(1). Alzheimer's Association (2020) 2020 Alzheimer's disease facts and figures. Alzheimer's Dementia 16, 391-460.

(2). Huang Y, and Mucke L (2012) Alzheimer mechanisms and therapeutic strategies. Cell 148, 1204 1222. [PubMed: 22424230]

(3). Selkoe DJ (2002) Alzheimer's disease is a synaptic failure. Science (Washington, DC, U. S.) 298, 789-791.

(4). Walsh DM, Klyubin I, Fadeeva JV, Cullen WK, Anwyl R, Wolfe MS, Rowan MJ, and Selkoe DJ (2002) Naturally secreted oligomers of amyloid $\beta$ protein potently inhibit hippocampal long-term potentiation in vivo. Nature 416, 535-539. [PubMed: 11932745]

(5). Lacor PN, Buniel MC, Furlow PW, Clemente AS, Velasco PT, Wood M, Viola KL, and Klein WL (2007) A $\beta$ oligomer-induced aberrations in synapse composition, shape, and density provide a molecular basis for loss of connectivity in Alzheimer's disease. J. Neurosci 27, 796-807. [PubMed: 17251419]

(6). Chen Y, Fu AKY, and Ip NY (2019) Synaptic dysfunction in Alzheimer's disease: Mechanisms and therapeutic strategies. Pharmacol. Ther 195, 186-198. [PubMed: 30439458]

(7). Selkoe DJ (2001) Alzheimer's disease: Genes, proteins, and therapy. Physiol. Rev 81, 741-766. [PubMed: 11274343]

(8). Selkoe DJ, and Hardy J (2016) The amyloid hypothesis of Alzheimer's disease at 25 years. EMBO Mol. Med 8, 595-608. [PubMed: 27025652]

(9). Jack CR, and Holtzman DM (2013) Biomarker modeling of alzheimer's disease. Neuron 80, 1347-1358. [PubMed: 24360540]

(10). Maia MA, and Sousa E (2019) BACE-1 and $\gamma$-secretase as therapeutic targets for alzheimer's disease. Pharmaceuticals 12, 41.

(11). Hemming ML, Elias JE, Gygi SP, and Selkoe DJ (2008) Proteomic Profiling of $\gamma$-Secretase Substrates and Mapping of Substrate Requirements. PLoS Biol. 6, e257. [PubMed: 18942891]

(12). Wolfe MS (2020) Unraveling the complexity of $\gamma$-secretase. Semin. Cell Dev. Biol, 30323.

(13). Li YM, Xu M, Lai MT, Huang Q, Castro JL, DiMuzlo-Mower J, Harrison T, Lellis C, Nadin A, Neduvelli JG, Register RB, Sardana MK, Shearman MS, Smith AL, Shi XP, Yin KC, Shafer JA, and Gardell SJ (2000) Photoactivated $\gamma$-secretase inhibitors directed to the active site covalently label presenilin 1. Nature 405, 689-694. [PubMed: 10864326] 
(14). Ahn K, Shelton CC, Tian Y, Zhang X, Gilchrist ML, Sisodia SS, and Li YM (2010) Activation and intrinsic $\gamma$-secretase activity of presenilin 1. Proc. Natl. Acad. Sci. U. S. A 107, 21435 21440. [PubMed: 21115843]

(15). Selkoe DJ (1999) Translating cell biology into therapeutic advances in Alzheimer's disease. Nature 399, A23-31. [PubMed: 10392577]

(16). Crump CJ, Johnson DS, and Li YM (2013) Development and mechanism of $\gamma$-secretase modulators for Alzheimer's disease. Biochemistry 52, 3197-3216. [PubMed: 23614767]

(17). Bursavich MG, Harrison BA, and Blain JF (2016) Gamma secretase modulators: New Alzheimer's drugs on the horizon? J. Med. Chem 59, 7389-7409. [PubMed: 27007185]

(18). Nie P, Vartak A, and Li YM (2020) $\gamma$-Secretase inhibitors and modulators: Mechanistic insights into the function and regulation of $\gamma$-Secretase. Semin. Cell Dev. Biol, 30276.

(19). Doody RS, Raman R, Farlow M, Iwatsubo T, Vellas B, Joffe S, Kieburtz K, He F, Sun X, Thomas RG, Aisen PS, Siemers E, Sethuraman G, and Mohs R (2013) A phase 3 trial of semagacestat for treatment of Alzheimer's disease. N. Engl. J. Med 369, 341-350. [PubMed: 23883379]

(20). Gu S, and Pei J (2017) Innovating Chinese herbal medicine: From traditional health practice to scientific drug discovery. Front. Pharmacol 8, 381. [PubMed: 28670279]

(21). Lemonnier N, Zhou G-B, Prasher B, Mukerji M, Chen Z, Brahmachari SK, Noble D, Auffray C, and Sagner M (2017) Traditional Knowledge-based Medicine: A Review of History, Principles, and Relevance in the Present Context of P4 Systems Medicine. Prog. Prev. Med 2, No. e0011.

(22). Wang J, Wong YK, and Liao F (2018) What has traditional Chinese medicine delivered for modern medicine? Expert Rev. Mol. Med 20, No. e4. [PubMed: 29747718]

(23). Bharate SS, Mignani S, and Vishwakarma RA (2018) Why Are the Majority of Active Compounds in the CNS Domain Natural Products? A Critical Analysis. J. Med. Chem 61, 10345-10374. [PubMed: 29989814]

(24). Fu AKY, Hung KW, Huang H, Gu S, Shen Y, Cheng EYL, Ip FCF, Huang X, Fu WY, and Ip NY (2014) Blockade of EphA4 signaling ameliorates hippocampal synaptic dysfunctions in mouse models of Alzheimer's disease. Proc. Natl. Acad. Sci. U. S. A 111, 9959-9964. [PubMed: 24958880]

(25). Ip FC, Fu W-Y, Cheng EY, Tong EP, Lok K-C, Liang Y, Ye W-C, and Ip NY (2015) Anemoside A3 enhances cognition through the regulation of synaptic function and neuroprotection. Neuropsychopharmacology 40, 1877-87. [PubMed: 25649278]

(26). Gao L, Li C, Wang Z, Liu X, You Y, Wei H, and Guo T (2015) Ligustri Lucidi Fructus as a traditional Chinese medicine: A review of its phytochemistry and pharmacology. Nat. Prod. Res 29, 493-510. [PubMed: 25244978]

(27). Ashour A, El-Sharkawy S, Amer M, Abdel Bar F, Katakura Y, Miyamoto T, Toyota N, Bang TH, Kondo R, and Shimizu K (2014) Rational design and synthesis of topoisomerase i and II inhibitors based on oleanolic acid moiety for new anti-cancer drugs. Bioorg. Med. Chem 22, 211-220. [PubMed: 24326278]

(28). Tian Y, Bassit B, Chau D, and Li YM (2010) An APP inhibitory domain containing the Flemish mutation residue modulates $\gamma$-secretase activity for AB production. Nat. Struct. Mol. Biol 17, 151-158. [PubMed: 20062056]

(29). Chau DM, Crump CJ, Villa JC, Scheinberg DA, and Li YM (2012) Familial Alzheimer disease presenilin-1 mutations alter the active site conformation of $\gamma$-secretase. J. Biol. Chem 287, 17288-17296. [PubMed: 22461631]

(30). Jankowsky JL, Fadale DJ, Anderson J, Xu GM, Gonzales V, Jenkins NA, Copeland NG, Lee MK, Younkin LH, Wagner SL, Younkin SG, and Borchelt DR (2004) Mutant presenilins specifically elevate the levels of the 42 residue beta-amyloid peptide in vivo: evidence for augmentation of a 42-specific gamma secretase. Hum. Mol. Genet 13, 159-170. [PubMed: 14645205]

(31). Gertsik N, Chau DM, and Li YM (2015) $\gamma$-Secretase Inhibitors and Modulators Induce Distinct Conformational Changes in the Active Sites of $\gamma$-Secretase and Signal Peptide Peptidase. ACS Chem. Biol 10, 1925-1931. [PubMed: 26030233]

(32). De Strooper B (2014) Lessons from a failed $\gamma$-secretase Alzheimer trial. Cell 159, 721-726. [PubMed: 25417150] 
(33). Geling A, Steiner H, Willem M, Bally-Cuif L, and Haass C (2002) A Gamma-Secretase Inhibitor Blocks Notch Signaling in Vivo and Causes a Severe Neurogenic Phenotype in Zebrafish. EMBO Rep. 3, 688-694. [PubMed: 12101103]

(34). Kreft A, Harrison B, Aschmies S, Atchison K, Casebier D, Cole DC, Diamantidis G, Ellingboe J, Hauze D, Hu Y, Huryn D, Jin M, Kubrak D, Lu P, Lundquist J, Mann C, Martone R, Moore W, Oganesian A, Porte A, Riddell DR, Sonnenberg-Reines J, Stock JR, Sun SC, Wagner E, Woller K, Xu Z, Zhou H, and Steven Jacobsen J (2008) Discovery of a novel series of Notch-sparing $\gamma$ secretase inhibitors. Bioorg. Med. Chem. Lett 18, 4232-4236. [PubMed: 18556202]

(35). Nelson AT, Camelio AM, Claussen KR, Cho J, Tremmel L, Digiovanni J, and Siegel D (2015) Synthesis of oxygenated oleanolic and ursolic acid derivatives with anti-inflammatory properties. Bioorg. Med. Chem. Lett 25, 4342-4346. [PubMed: 26259803]

(36). Raghuvanshi DS, Verma N, Singh S, Luqman S, Chand Gupta A, Bawankule DU, Tandon S, Nagar A, Kumar Y, and Khan F (2018) Design and synthesis of novel oleanolic acid based chromenes as anti-proliferative and anti-inflammatory agents. New J. Chem 42, 16782-16794.

(37). Siewert B, Pianowski E, Obernauer A, and Csuk R (2014) Towards cytotoxic and selective derivatives of maslinic acid. Bioorg. Med. Chem 22, 594-615. [PubMed: 24268794]

(38). Sommerwerk S, Heller L, Kuhfs J, and Csuk R (2016) Urea derivates of ursolic, oleanolic and maslinic acid induce apoptosis and are selective cytotoxic for several human tumor cell lines. Eur. J. Med. Chem 119, 1-16. [PubMed: 27149037]

(39). Ghosh AK, and Brindisi M (2015) Organic Carbamates in Drug Design and Medicinal Chemistry. J. Med. Chem 58, 2895-2940. [PubMed: 25565044]

(40). Duggan ME, and Imagire JS (1989) Copper(I) Chloride Catalyzed Addition of Alcohols to Alkyl 1socyanatesA Mild and Expedient Method for Alkyl Carbamate Formation. Synthesis 1989, 131132.

(41). Viana da Silva S, Haberl MG, Zhang P, Bethge P, Lemos C, Goncalves N, Gorlewicz A, Malezieux M, Goncalves FQ, Grosjean N, Blanchet C, Frick A, Nagerl UV, Cunha RA, and Mulle C (2016) Early synaptic deficits in the APP/PS1 mouse model of Alzheimer's disease involve neuronal adenosine A2A receptors. Nat. Commun 7, 11915. [PubMed: 27312972]

(42). Findeis M, Schroeder F, Creaser S, McKee T, and Xia W (2015) Natural Product and Natural Product-Derived Gamma Secretase Modulators from Actaea Racemosa Extracts. Medicines 2, 127-140. [PubMed: 28930205]

(43). Wu X, Cai H, Pan L, Cui G, Qin F, Li Y, and Cai Z (2019) Small Molecule Natural Products and Alzheimer's Disease. Curr. Top. Med. Chem 19, 187-204. [PubMed: 30714527]

(44). Tan Y, Zhang QG, Wong S, and Hua Q (2015) Anti-Alzheimer Therapeutic Drugs Targeting?Secretase. Curr. Top. Med. Chem 16, 549-557.

(45). Yagi A, Okamura N, Haraguchi Y, Noda K, and Nishioka I (1978) Studies on the constituents of Zizyphi fructus. II. Structure of new p-coumaroylates of maslinic acid. Chem. Pharm. Bull 26, 3075-3079.

(46). Ma J, Starck SR, and Hecht SM (1999) DNA polymerase $\beta$ inhibitors from Tetracera boiviniana. J. Nat. Prod 62, 1660-1663. [PubMed: 10654414]

(47). Guan B, Peng CC, Zeng Q, Cheng XR, Yan SK, Jin HZ, and Zhang WD (2013) Cytotoxic pentacyclic triterpenoids from prinsepia utilis. Planta Med. 79, 365-368. [PubMed: 23479388]

(48). Che CT, and Wong MS (2015) Ligustrum lucidum and its constituents: A mini-review on the anti-osteoporosis potential. Nat. Prod. Commun 10, 2189-2194. [PubMed: 26882695]

(49). Pang Z, Zhi-Yan Z, Wang W, Ma Y, Feng-Ju N, Zhang X, and Han C (2015) The advances in research on the pharmacological effects of Fructus Ligustri Lucidi. BioMed Res. Int 2015, 281873. [PubMed: 25874204]

(50). Cai H, Luo Y, Yan X, Ding P, Huang Y, Fang S, Zhang R, Chen Y, Guo Z, Fang J, Wang Q, and $\mathrm{Xu} J$ (2018) The Mechanisms of Bushen-Yizhi Formula as a Therapeutic Agent against Alzheimer's Disease. Sci. Rep 8, 3104. [PubMed: 29449587]

(51). Fu G, Ip FCF, Pang H, and Ip NY (2010) New secoiridoid glucosides from ligustrum lucidum induce erk and creb phosphorylation in cultured cortical neurons. Planta Med. 76, 998-1003. [PubMed: 20143293] 
(52). Shelton CC, Zhu L, Chau D, Yang L, Wang R, Djaballah H, Zheng H, and Li YM (2009) Modulation of $\gamma$-secretase specificity using small molecule allosteric inhibitors. Proc. Natl. Acad. Sci. U. S. A 106, 20228-20233. [PubMed: 19906985]

(53). Crump CJ, Castro SV, Wang F, Pozdnyakov N, Ballard TE, Sisodia SS, Bales KR, Johnson DS, and Li YM (2012) BMS-708,163 targets presenilin and lacks notch-sparing activity. Biochemistry 51, 7209-7211. [PubMed: 22931393]

(54). Osenkowski P, Ye W, Wang R, Wolfe MS, and Selkoe DJ (2008) Direct and potent regulation of $\gamma$-secretase by its lipid microenvironment. J. Biol. Chem 283, 22529-22540. [PubMed: 18539594]

(55). Wager TT, Hou X, Verhoest PR, and Villalobos A (2016) Central Nervous System Multiparameter Optimization Desirability: Application in Drug Discovery. ACS Chem. Neurosci 7, 767-775. [PubMed: 26991242]

(56). Guinda Á, Pérez-Camino MC, and Lanzón A (2004) Supplementation of oils with oleanolic acid from the olive leaf (olea europaea). Eur. J. Lipid Sci. Technol 106, 22-26.

(57). Pollier J, and Goossens A (2012) Oleanolic acid. Phytochemistry 77, 10-15. [PubMed: 22377690]

(58). Li YM, Lai MT, Xu M, Huang Q, DiMuzio-Mower J, Sardana MK, Shi XP, Yin KC, Shafer JA, and Gardell SJ (2000) Presenilin 1 is linked with $\gamma$-secretase activity in the detergent solubilized state. Proc. Natl. Acad. Sci. U. S. A 97, 6138-6143. [PubMed: 10801983]

(59). Xu H, Gouras GK, Greenfield JP, Vincent B, Naslund J, Mazzarelli L, Fried G, Jovanovic JN, Seeger M, Relkin NR, Liao F, Checler F, Buxbaum JD, Chait BT, Thinakaran G, Sisodia SS, Wang R, Greengard P, and Gandy S (1998) Estrogen reduces neuronal generation of Alzheimer $\beta$-amyloid peptides. Nat. Med 4, 447-451. [PubMed: 9546791]

(60). Thinakaran G, Borchelt DR, Lee MK, Slunt HH, Spitzer L, Kim G, Ratovitsky T, Davenport F, Nordstedt C, Seeger M, Hardy J, Levey AI, Gandy SE, Jenkins NA, Copeland NG, Price DL, and Sisodia SS (1996) Endoproteolysis of presenilin 1 and accumulation of processed derivatives in vivo. Neuron 17, 181-190. [PubMed: 8755489]

(61). Netzer WJ, Dou F, Cai D, Veach D, Jean S, Li Y, Bornmann WG, Clarkson B, Xu H, and Greengard P (2003) Gleevec inhibits $\beta$-amyloid production but not Notch cleavage. Proc. Natl. Acad. Sci. U. S. A 100, 12444-12449. [PubMed: 14523244]

(62). Tian Y, Crump CJ, and Li YM (2010) Dual role of $a$-secretase cleavage in the regulation of $\gamma$ secretase activity for amyloid production. J. Biol. Chem 285, 32549-32556. [PubMed: 20675367] 

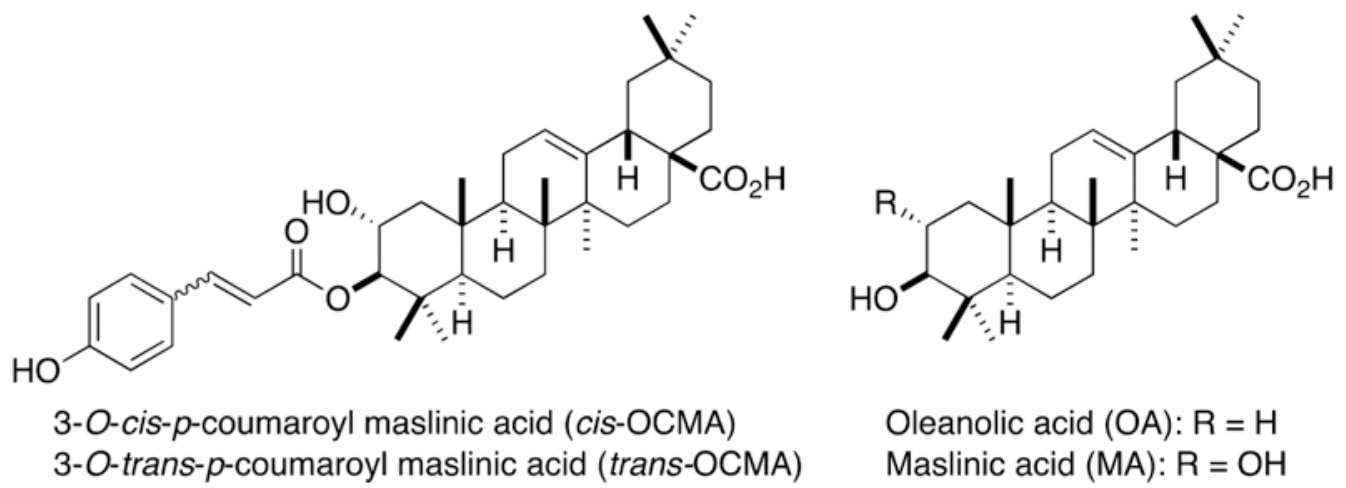

Figure 1.

Structure of naturally occurring pentacyclic triterpenes in L. Iucidum. Shown are stereoisomeric maslinic acid (MA) derivatives (left) as the major components in active RF9C31 and RF9-C32 fractions and their congeners (right) found abundantly in L. lucidum. 
A

RF9-C24 C25 C26 C27 C28 C29 C30 C31 C32 Con
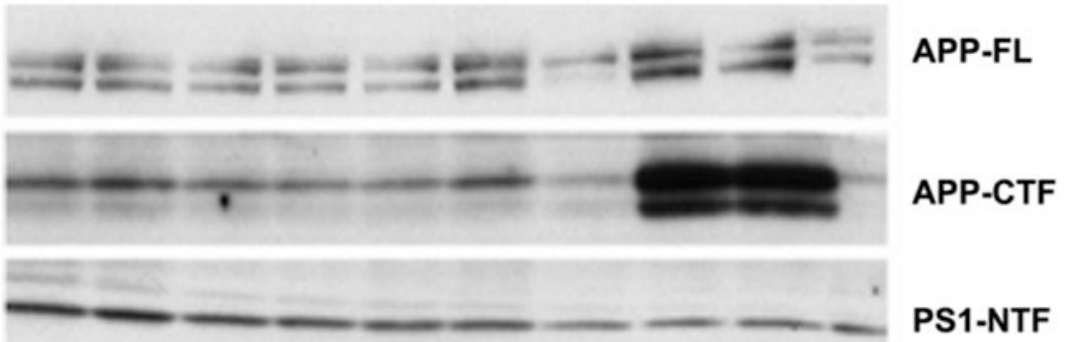

B
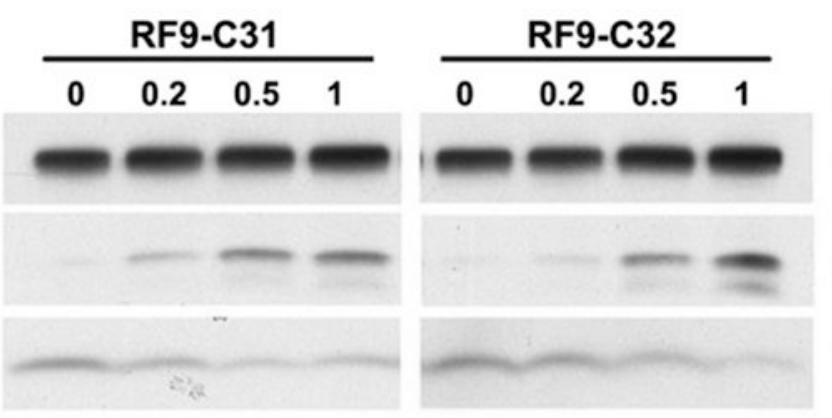

$(\mu \mathrm{M})$

APP-FL

APP-CTF

Total $\mathbf{A} \beta$

C

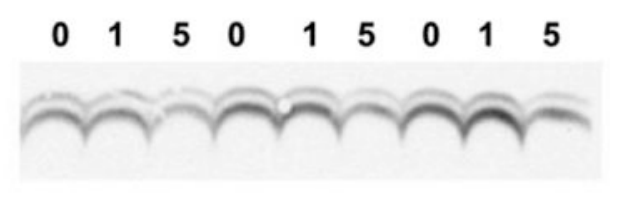

RF9-C31 ( $\mu \mathrm{M})$

A $\beta 1-40 / 42$

A $\beta 11-40 / 42$

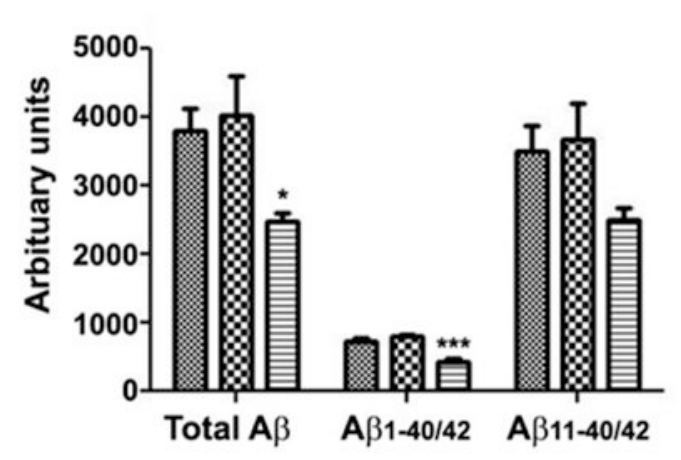

$(\mu \mathrm{M})$

曲 0

回 5

Figure 2.

Active fractions RF9-C31 and RF9-C32 from L. lucidum extracts induced APP-CTF accumulation and reduced $\mathrm{A} \beta$ production. (A) N2a695 cells were treated with fractions (10 $\mu \mathrm{M}$ ) isolated from L. lucidum for $24 \mathrm{~h}$. Representative Western blots showing the levels of full-length APP (APP-FL), APP-CTF, and presenilin-1 NTF (PS1-NTF). (B) Dose-response effects of RF9-C31 and RF9-C32 on APP-CTF and total A $\beta$ levels. N2a695 cells were treated with RF9-C31 or RF9-C32 for $24 \mathrm{~h}$. (C) RF9-C31 reduced endogenous production of A $\beta_{1-40 / 42}$. Primary rat prenatal cortical neurons were pretreated with RF9-C31 and metabolically labeled with ${ }^{35} \mathrm{~S}$-methionine/cysteine protein mix in the presence of RF9-C31. 
Immunoprecipitated $\mathrm{A} \beta$ species from the conditioned media were subjected to SDS-PAGE and autoradiography (upper), and quantification analysis is shown as a bar graph (lower) $\left({ }^{*} P\right.$ $<0.05, * * * P<0.005$ vs control; one-way ANOVA). 
A
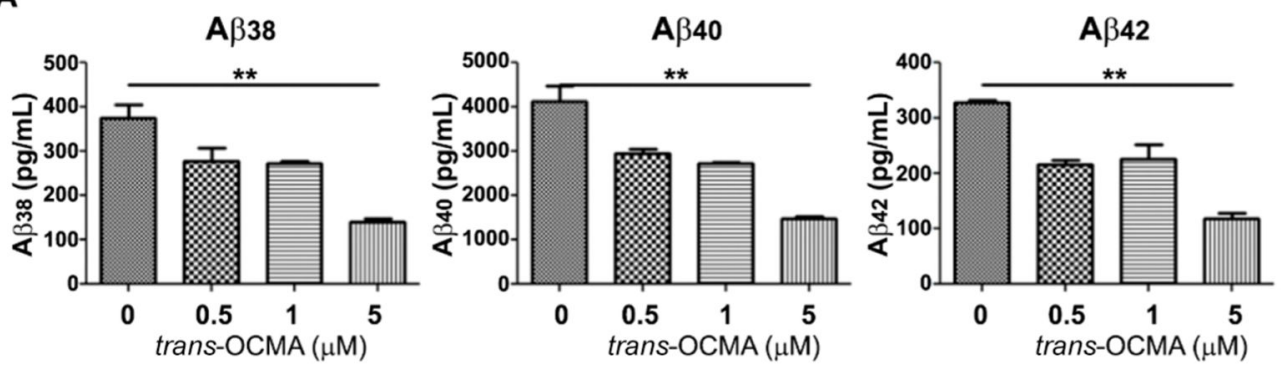

B

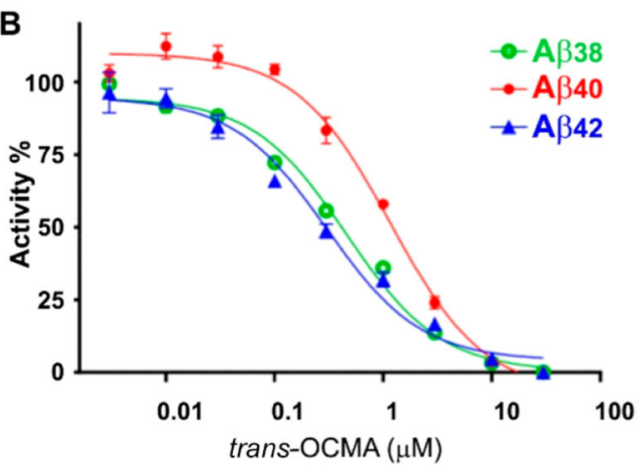

C

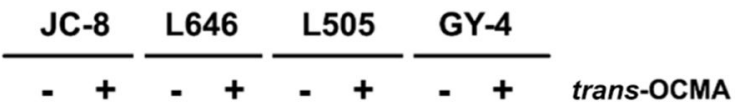

D

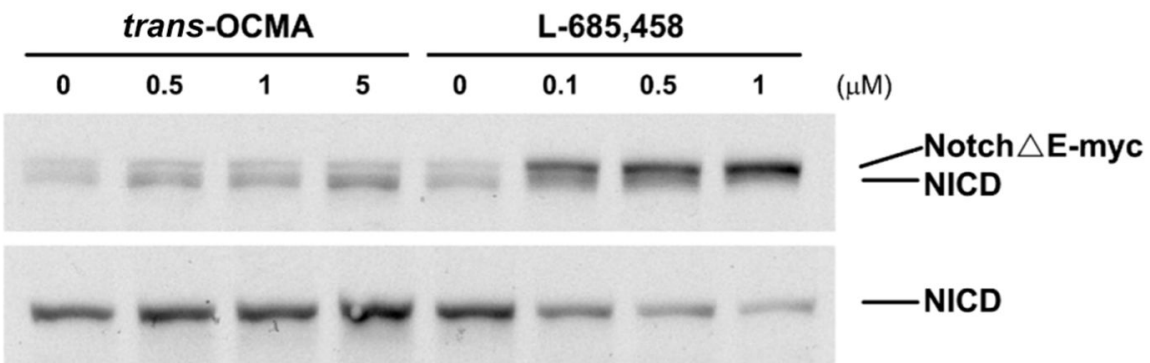

Figure 3.

trans-OCMA specifically inhibits $\mathrm{A} \beta$ production by regulating GS activity without affecting Notch1 cleavage. (A) APP-CTF-expressing N2a cells were treated with trans-OCMA for 24 $\mathrm{h}$. The dose-response relationships between trans-OCMA treatment and $\mathrm{A} \beta_{38}, \mathrm{~A} \beta_{40}$, or $\mathrm{A} \beta_{42}$ production were determined by amyloid triplex assay. Statistical analysis was performed by one-way ANOVA. Data are presented as mean $\pm \mathrm{SD}(* * P<0.01)$. (B) transOCMA inhibited $\mathrm{A} \beta_{38}, \mathrm{~A} \beta_{40}$, and $\mathrm{A} \beta_{42}$ production in a membrane-based in vitro GS activity assay. (C) trans-OCMA selectively blocked the binding of GY-4 to the PS1 active site (PS1-NTF). (D) trans-OCMA did not affect the GS-mediated production of NICD from Notch $\Delta$ E-myc. Upper panel: Full-length Notch $\Delta \mathrm{E}$ (upper band) and its cleavage product, NICD (lower band), were detected with an anti-myc antibody. Lower panel: NICD cleavage fragment was recognized by an anti-NICD antibody.

ACS Chem Neurosci. Author manuscript; available in PMC 2021 September 16. 

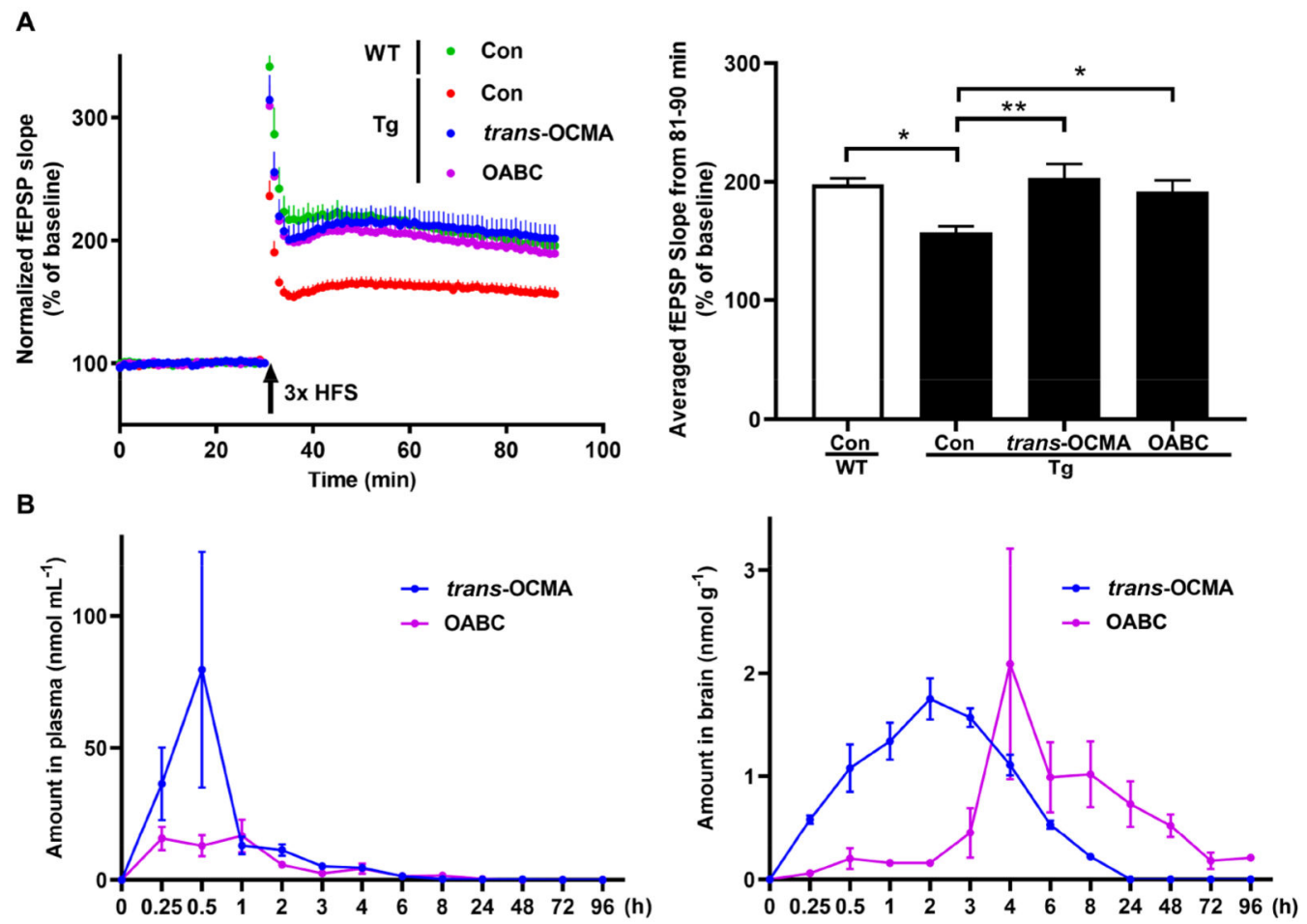

Figure 4.

trans-OCMA and OABC rescue LTP deficits in APP/PS1 mice and can cross the bloodbrain barrier. (A) APP/PS1 (Tg) or wild-type (WT) mice were intraperitoneally injected with trans-OCMA or OABC at $85 \mu \mathrm{mol} / \mathrm{kg}$ or vehicle control (Con) for 4 weeks (see Methods).

Data represent averaged slopes of baseline-normalized fEPSP (mean \pm SEM). Trace recordings $30 \mathrm{~min}$ before and $60 \mathrm{~min}$ after LTP induction by high-frequency stimulation (HFS) are shown (left). Quantification of mean fEPSP slopes in the last 10 min of recording after LTP induction (data are mean \pm SEM; $n=5-6$ slices from 3 brains per condition). Statistical significance was assessed by one-way ANOVA followed by the Bonferroni multiple comparison test $(* P<0.05, * * P<0.01)$ (right). (B) Detection of trans-OCMA and $\mathrm{OABC}$ in the plasma and brain of $\mathrm{C} 57 \mathrm{BL} / 6$ mice after a single intraperitoneal injection. 
Table 1.

Structures of OA and MA Derivatives and Intermediates Produced along the Synthesis of trans-OCMA as Well as Their Effects on $\mathrm{A} \beta$ Production

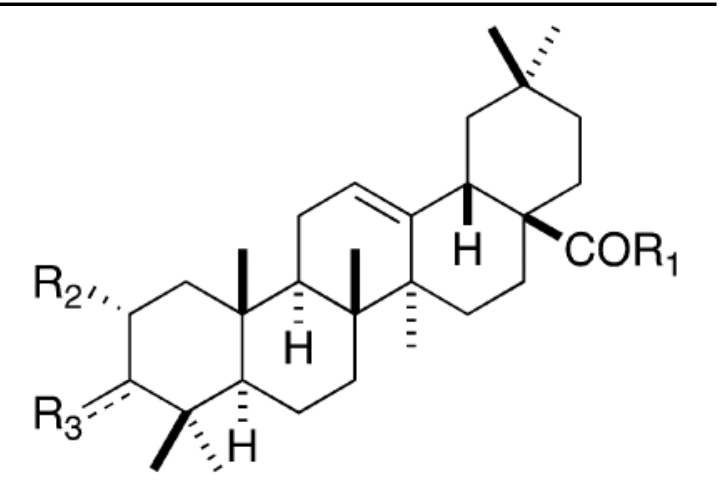

\begin{tabular}{|c|c|c|c|c|}
\hline compd ID & $\mathbf{R}_{\mathbf{1}}$ & $\mathbf{R}_{2}$ & $\mathbf{R}_{3}$ & $\% \mathbf{A} \beta_{40}, \mathbf{A} \beta_{42}$ \\
\hline $\mathrm{OA}^{a}$ & $\mathrm{OH}$ & $\mathrm{H}$ & $\mathrm{OH}$ & 115,123 \\
\hline OA-1 & OBn & $\mathrm{H}$ & OAc & 66,55 \\
\hline $\mathrm{OA}-2$ & $\mathrm{OBn}$ & $\mathrm{H}$ & $=\mathrm{O}$ & 53,98 \\
\hline OA-3 & $\mathrm{OMe}$ & $\mathrm{H}$ & $=\mathrm{O}$ & 84,200 \\
\hline $\mathrm{OA}-4$ & NHBn & $\mathrm{H}$ & OAc & 130,226 \\
\hline $\mathrm{OABC}^{a}$ & $\mathrm{OH}$ & $\mathrm{H}$ & OCONHBn & 60,67 \\
\hline MA-1 & $\mathrm{OBn}$ & $\mathrm{OH}$ & $\mathrm{OH}$ & 67,118 \\
\hline MA-2 & $\mathrm{OBn}$ & $\mathrm{OH}$ & $=\mathrm{O}$ & 120,200 \\
\hline MA-3 & NHBn & OAc & OAc & 87,198 \\
\hline MA- $4^{b}$ & $\mathrm{NHCH}_{2} \mathrm{Bn}$ & $\mathrm{OH}$ & $\mathrm{OH}$ & 81,250 \\
\hline MA $-5^{b}$ & $\mathrm{NHCH}_{2} \mathrm{Bn}$ & OAc & OAc & 66,146 \\
\hline
\end{tabular}

${ }^{a}$ Also see SI Figure S5.

${ }^{b}$ Toxic to cells. A $\beta$ : amyloid-beta, MA: maslinic acid, OA: oleanolic acid. 


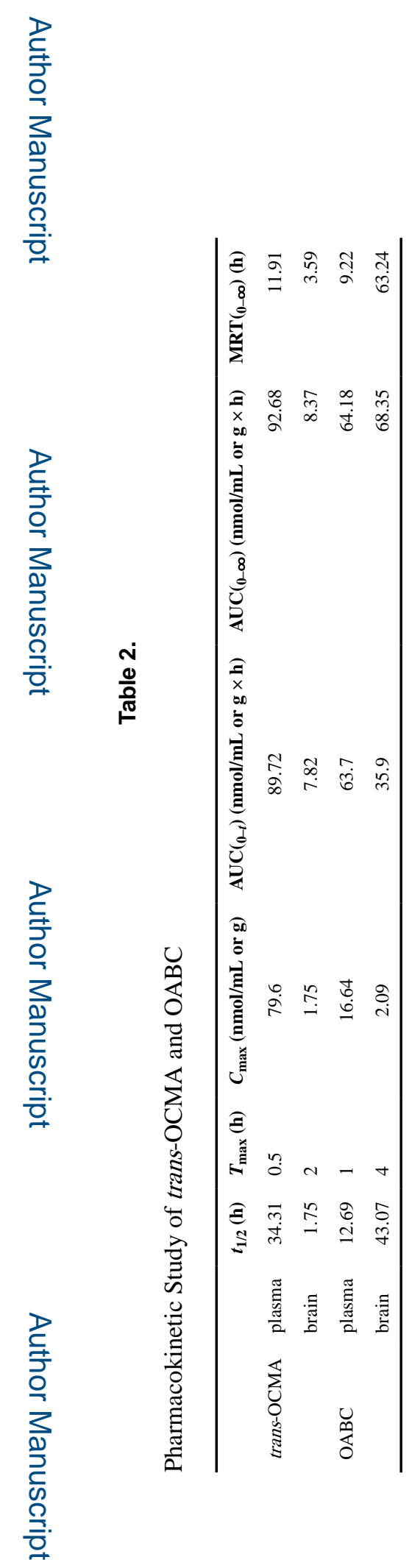

ACS Chem Neurosci. Author manuscript; available in PMC 2021 September 16. 